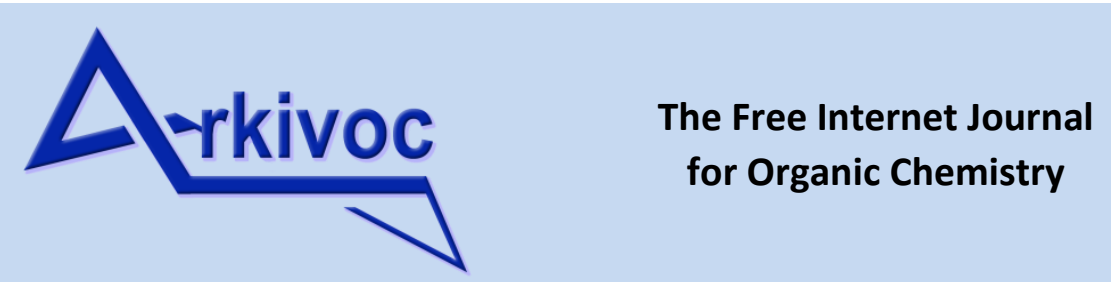

The Free Internet Journal

for Organic Chemistry

Paper

Archive for

Organic Chemistry

Arkivoc 2020, part vii, 365-378

\title{
An efficient and scalable synthesis of thiazolo ring fused 2-pyridones using flow chemistry
}

\author{
Andrew G. Cairns, ${ }^{\text {a }}$ Souvik Sarkar, ${ }^{a}$ Pardeep Singh, ${ }^{a}$ Andreas Larsson, ${ }^{* b}$ and Fredrik Almqvist ${ }^{* a, c}$ \\ a Department of Chemistry, Umeå University, 90187 Umeå, Sweden \\ ${ }^{b}$ FOI, Swedish Defence Research Agency, CBRN Defence \& Security, SE 901 82, Umeå, Sweden \\ 'Umeå Centre for Microbial Research, Umeå University, SE-90187 Umeå, Sweden \\ Email: fredrik.almqvist@umu.se, andreas.larsson@foi.se
}

Dedicated to Professor Jan Bergman on the occasion of his 80th birthday

Received 12-08-2020

Accepted 02-11-2021

Published on line $02-16-2021$

\section{Abstract}

Thiazolino ring fused 2-pyridones are a valuable scaffold with varied and substitution dependent biological activity, accessed primarily by an acyl ketene-imine cycloaddition and rearrangement. Although powerful, some aspects of this chemistry such as the requirement for excess starting material and the production of gas can make larger scale synthesis challenging. Here we describe the development, application and scaling of a continuous flow process allowing larger scale synthesis, with better handling of hazards and more reliable scaling. Optimisation and control of conditions allows for a more efficient synthesis, with a lower equivalence of the acyl ketene precursor required.

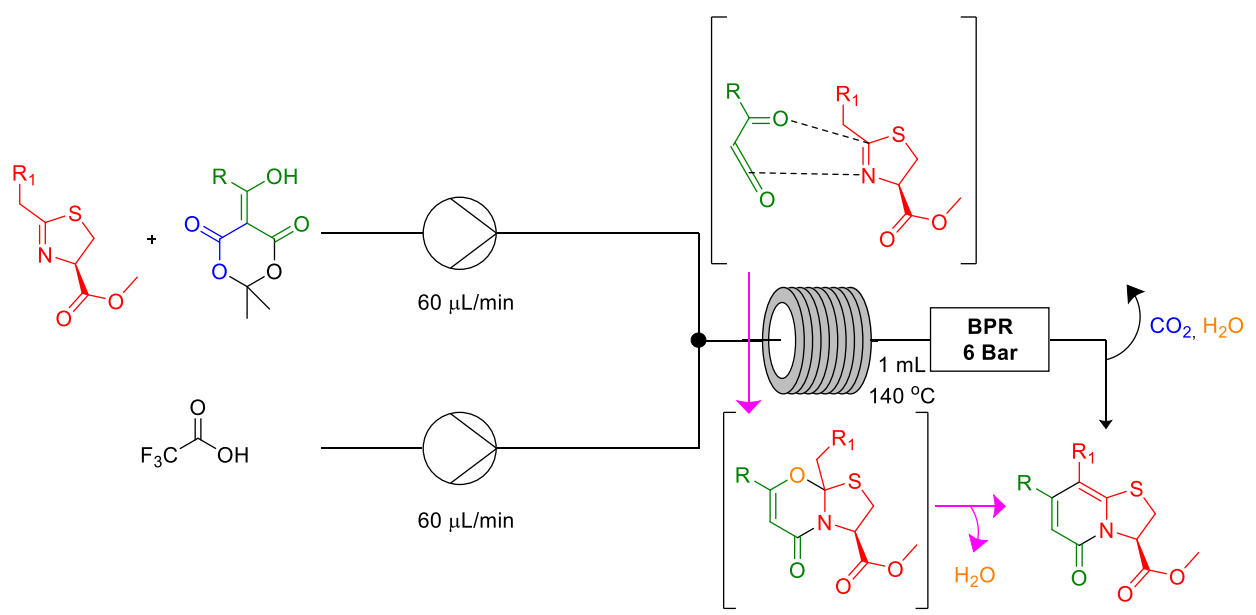

Keywords: Flow chemistry, pyridone, thiazolo, heterocycle, acyl ketene, design of experiments 


\section{Introduction}

The ring fused 2-pyridone backbone has proven to be an invaluable starting point in the development of small molecules with selective biological activity. Differentially substituted variants of this privileged scaffold have previously shown activity as virulence inhibitors in E. coli. ${ }^{1-2}$ Listeria and Chlamydia infections ${ }^{3-5}$ and modulators of protein aggregation associated with neurodegenerative diseases. ${ }^{6-13}$ In a recent study, a cyclopropyl analogue (Figure 1, A) was shown to inhibit Mycobacterium tuberculosis (Mtb) ability to convert into its tolerant state. These compounds were named Mycobacterial Tolerance Inhibitors (MTIs) and besides sensitizing Mtb to host defense responses (e.g. oxidative stress and low $\mathrm{pH}$ ) the most striking effect was that MTIs could make isoniazid resistant $M t b$ sensitive to the front line antibiotic isoniazid again. ${ }^{14}$ While the structure activity relationship (SAR) observed varies depending on the specific application, the combination of a rigid, peptide mimicking face and a heterocyclic framework with drug-like properties has proven widely applicable.

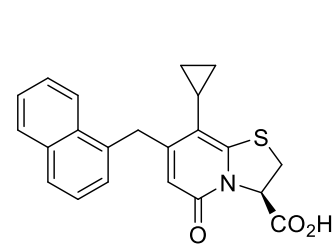

A

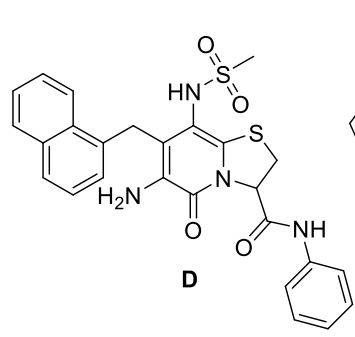

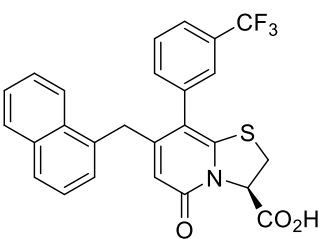

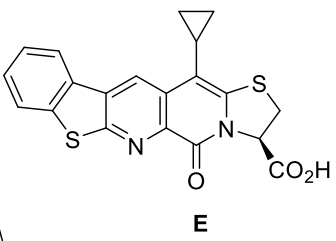

E

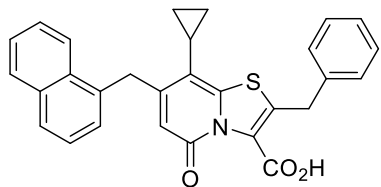

C

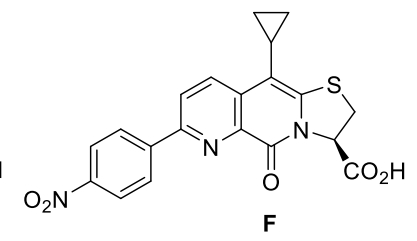

Figure 1. Biologically active thiazolino-2-pyridones.

The transformation used to form these heterocycles was first discovered in an attempted $\beta$-lactam synthesis. Briefly, it comprises an acyl ketene-imine cycloaddition from an Meldrum's acid analogue and subsequent acid catalyzed rearrangement. ${ }^{15}$ Numerous approaches have been developed for the direct functionalization of multiple positions on the bicyclic scaffold as well as its ring opening/expansion ${ }^{13,16-18}$ and annulation with different heterocycles. (Figure 2).

However, all these approaches require access to the initial scaffold. The underlying methodology is powerful; multiple bonds and a new ring system is produced from simple, readily accessible starting materials. The reaction is relatively quick, ${ }^{19}$ maintains the incorporated stereochemistry and tolerates a wide range of chemical functionality. 


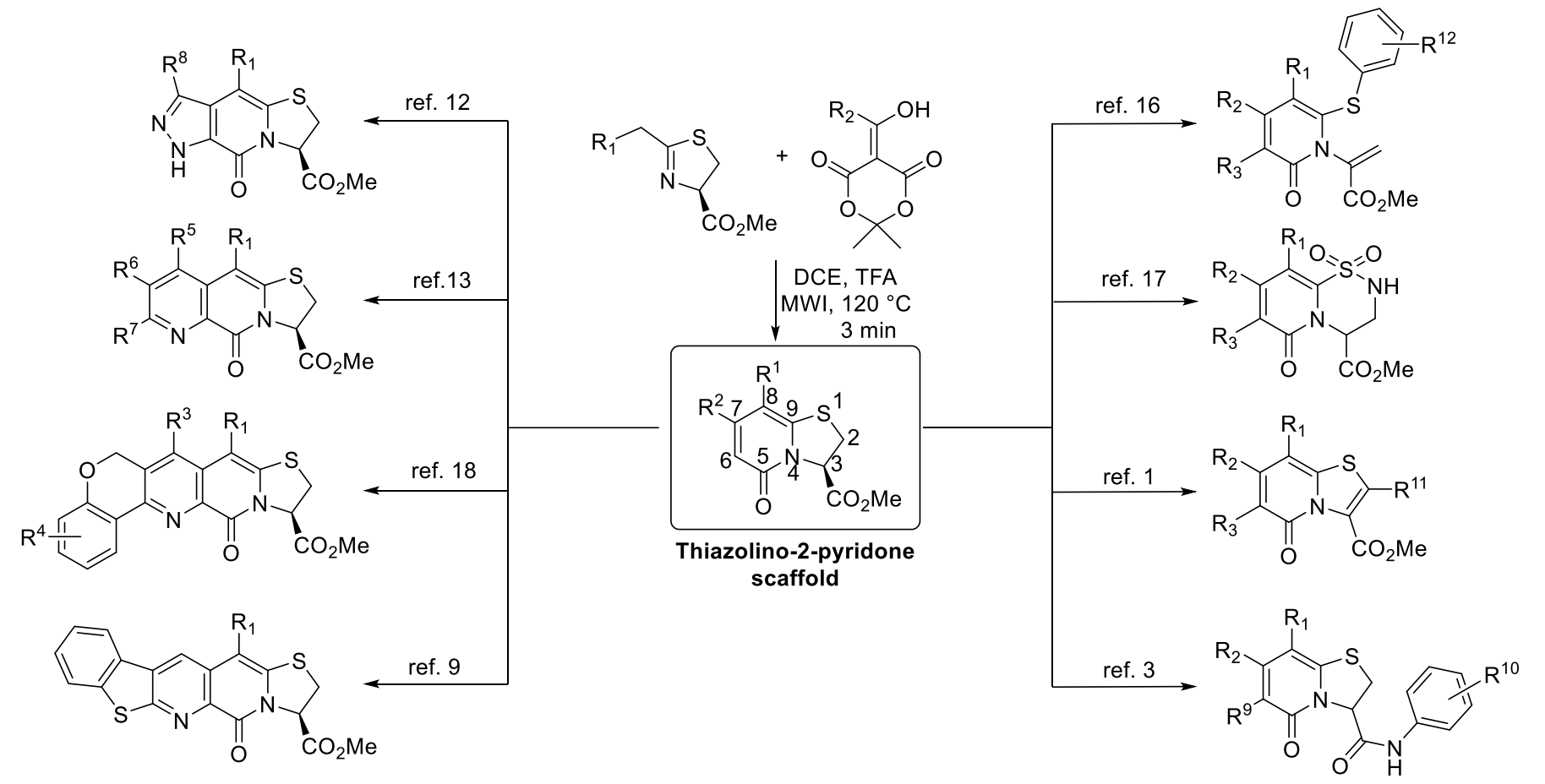

Figure 2. Synthetic applications of ring fused thiazolino-2-pyridones.

There are, as with many synthetic procedures, some specific limitations of this approach. High equivalence of the acyl Meldrum's acids, which are synthesized, are usually required for good conversion, and the high temperatures and acidic conditions are not compatible with all functionalities. Side products resulting from the excess acyl Meldrum's acid cause impurities in sufficiently large quantities to require chromatographic purification. As the optimal reaction temperatures are in excess of the solvent boiling point, sealed vessels are used. Microwave heating can be used, but this typically limits the scale of reaction ${ }^{20}$ and requires high concentrations of material to maximize throughput. At these higher concentrations, acyl Meldrum's acid starting materials differ substantially in the portion of material in solution and subsequent reactant concentration. Additionally, these conditions may decompose acyl Meldrum's acid below the optimal temperatures for subsequent cycloaddition, and slow or variable heating rates can effect yields. The $\mathrm{CO}_{2}(\mathrm{~g})$ generated also causes significant pressure, which represents a hazard. As analogues based on the scaffold are further developed and progress, larger quantities of material are required and these scaling issues are more problematic.

One approach to developing safe ${ }^{21}$ and readily scalable procedures for chemistries involving unstable intermediates and intense conditions is flow chemistry. ${ }^{22-26}$ This approach has been successfully applied to heterocycle synthesis, ${ }^{27-28}$ cycloadditions $^{29-30}$ and even to acyl ketene formation, ${ }^{31}$ and recent developments continue to show the potential flexibility ${ }^{32}$ and portability ${ }^{33}$ of this approach. Flow chemistry is often greener ${ }^{34}$ than batch chemistry, and sometimes allows access to transformations near impossible ${ }^{35}$ under batch conditions. At one point a mostly academic pursuit, ${ }^{36}$ continuous flow approaches are of increasing interest for pharmaceutical API production. ${ }^{36-37}$ 


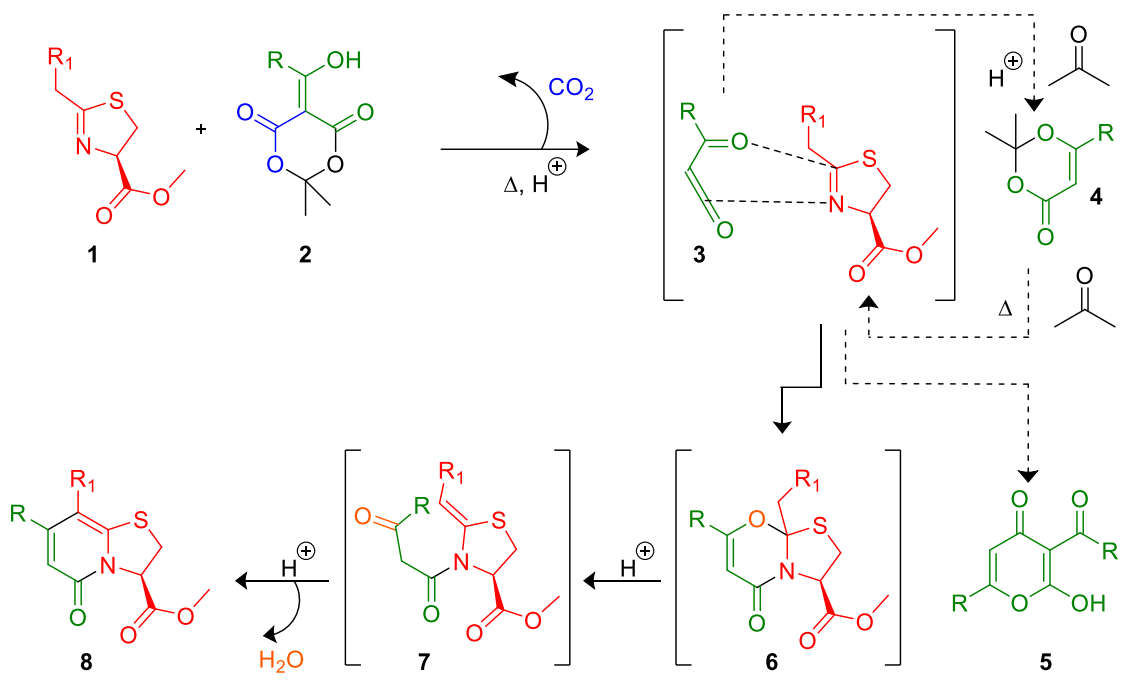

Figure 3. Synthetic applications of ring fused thiazolino-2-pyridones.

To evaluate the amenability of our procedure to a flow chemistry synthesis, we first considered the mechanism. Understanding of this transformation has been refined over time; later research demonstrated that the intermediate reacting with thiazoline 1 likely took the form of an $\alpha$-oxoketene (3), ${ }^{38}$ with analogous reactions on related frameworks suggesting initial formation of a 1,3-oxazine-4-one $6,{ }^{39}$ followed by ring opening to 7 and acid catalyzed cyclocondensation and aromatization to give the final fused 2-pyridone form $\mathbf{8}$ (Figure 3). It is well established that dehydroacetic acid analogues (5) are major products of acyl-ketene self-dimerisation, ${ }^{40-41}$ but recent results suggest that the acetone byproduct of decomposition can reversibly react with acyl-ketenes to form dioxin-4-one 4 , potentially acting as a store of this reactive intermediate. ${ }^{31}$

Some of the advantages to scaling our ketene-imine cycloaddition process in a flow setting are practical and obvious; heating and subsequent gas generation occur in only a small portion of our material at any time, and the $\mathrm{CO}_{2}(\mathrm{~g})$ is continually vented. As such, pressure build up in sealed containers is avoided. Scale can be adjusted by extending the run time, rather than running numerous batches for combination, and the containment available for the whole system is more robust than a series of microwave vials.

There are a few other advantages arguably less immediately obvious. Among these is improved and scalable mixing: in general, reagent mixing is more efficient in flow systems. ${ }^{22,26,36,42-44}$ In our system, where a reactive intermediate is generated in-situ and multiple steps occur within a short reaction time, efficient mixing is potentially important. Further, batch processes are frequently carried out at concentrations above the room temperature acyl Meldrum's acid solubility in order to maximize output; this increases the demand for efficient mixing. Increasing scale is much less demanding using a flow procedure and a lower concentration can be used. Variations in scale, concentration and vessel headspace can make the distribution between liquid and gas phases variable in our batch process. This is potentially important as both TFA (required for multiple steps) and our acetone byproduct boil below the reaction temperature. As previously mentioned, the acyl-ketene $\mathbf{3}$ would be expected to react reversibly with acetone to give 4, which effectively lowers the concentration but preserves the lifespan of our acyl-ketene. ${ }^{31}$ As such, the variation in headspace and pressure which would accompany changes in scale and vessel size may affect our process. ${ }^{22}$ Probably most importantly, the heat transfer properties of flow reactors are usually superior, and we made use of a glass rather than polymer microfluidic reactor to maintain this advantage. ${ }^{25}$ This improved heat transfer ${ }^{20,}{ }^{25}$ manifests as narrower temperature gradients, and these tighter temperature distributions help limit side reactions. ${ }^{22}$ Additionally, the change in heat transfer with tube diameter scales in a linear fashion. ${ }^{26}$ 


\section{Results and Discussion}

\section{Design of Experiments (DoE):}

Another practical advantage of flow chemistry is the capacity to perform numerous trial experiments sequentially under tightly controlled conditions. In order to optimize our search for improved reaction conditions we made use of a Design of Experiments (DoE) approach in order to simultaneously optimize for multiple variables. ${ }^{45}$ Conversion was assessed by ${ }^{1} \mathrm{H}$ NMR comparison of the residual thiazoline $\mathbf{1 0}$ to the newly formed pyridone. For this, the synthesis of simple napthyl pyridone $\mathbf{1 1}$ was used (Scheme 1). Microwave syntheses of this pyridone typically give yields of $60-70 \%$ using 2.75 equivalents acyl ketene precursor. As such, there is room both for improvements in yield and reduction in excess starting reagents.

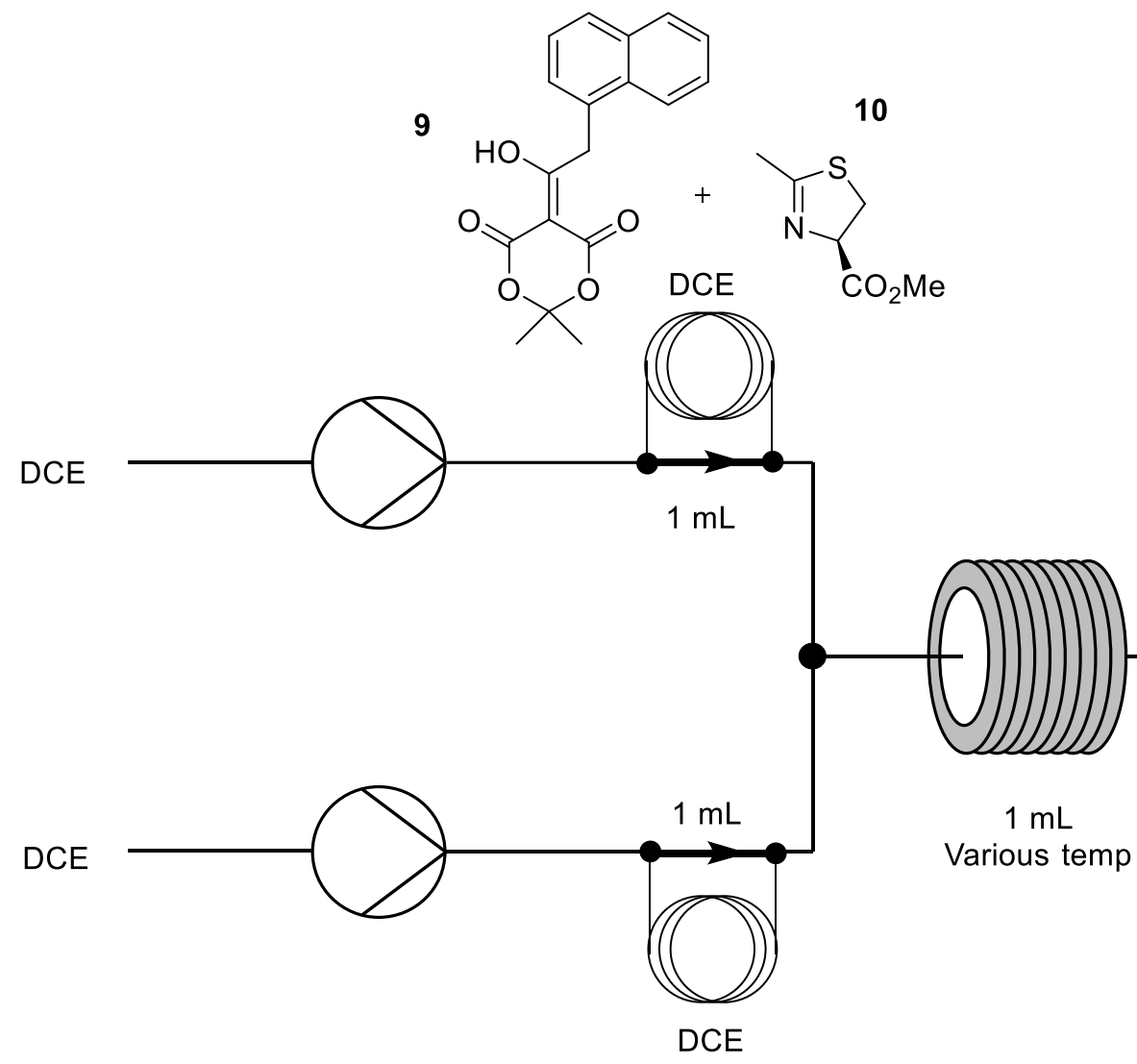

Acid
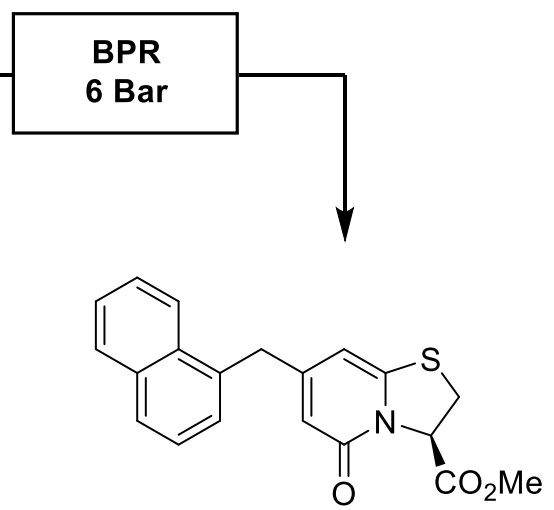

11

Scheme 1. The set-up for the flow system during the optimisation.

\section{Acid screen}

Trifluoroacetic acid ${ }^{38}$ is normally used, but both stronger ${ }^{15}$ and weaker ${ }^{46}$ acids have been employed previously. We re-investigated this variable under flow conditions using methanesulfonic, trifluoroacetic and acetic acids for a reasonable pKa variation. We simultaneously screened a limited range of concentrations - as the relative rates of ketene formation, cycloaddition, ring opening and condensation are both unknown and likely substrate dependent, it is unclear what the optimal concentration and pKa might be from mechanistic considerations. Our results suggest TFA remains the optimal choice, with very little reaction in particular where the weaker acetic acid was employed. Further, a higher equivalence of acid proved preferable and gave greater improvement where more equivalents of acyl ketene precursor were employed. 


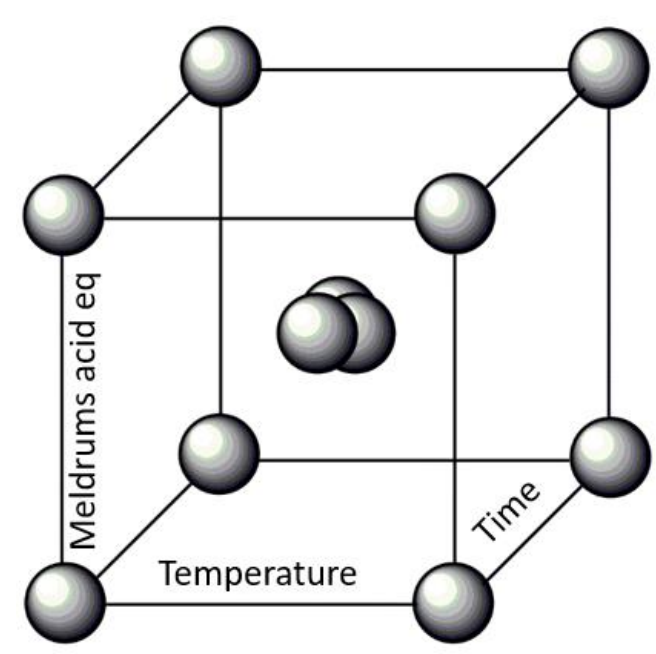

a

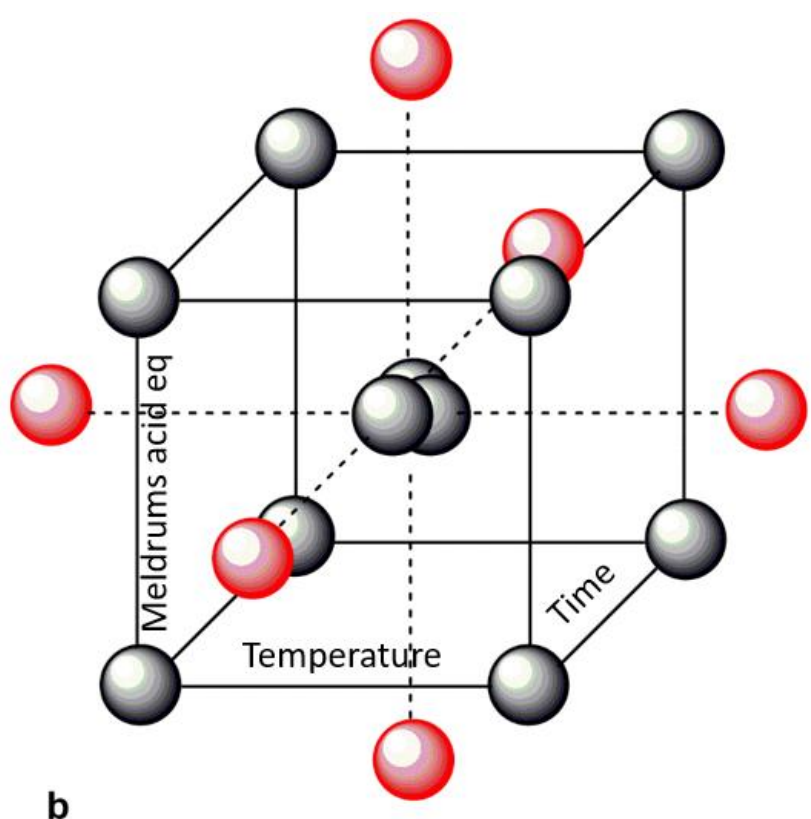

b

Figure 4. (a) Screening design for 2-pyridone synthesis. A full factorial design using four variables - temperature, reaction time, equivalents of Meldrum's acid derivative, and concentration of thiazoline (not shown) - resulting in a total of 19 experiments including three central points. (b) Optimisation design for 2-pyridone synthesis. A central composite design using three variables - temperature, reaction time, and equivalents of Meldrum's acid derivative - resulting in a total of 17 experiments including three central points.

\section{Initial screen}

For our initial screen, a full factorial design using four different variables were created (see Figure 5a and Table 1 , Entry 1-19). The variables chosen were time (1-5 minutes), temperature $\left(100-140{ }^{\circ} \mathrm{C}\right)$, concentration $(0.18$ $0.38 \mathrm{M}$, with respect to thiazoline) and equivalence of Meldrum's acid derivative (1-3). Calculated conversions from the 19 experiments were correlated with the different variables using multiple linear regression (MLR). This gave a model with ten coefficients which explained $95 \%$ of the variation in the response $(R 2 Y=0.95)$ and had good predictive properties according to cross-validation with a Q2 of 0.87 . The regression coefficients (Figure 5a) revealed that, within the range studied, concentration had no significant effect on conversion. Unsurprisingly, increased ketene precursor equivalents lead to higher conversion, but more importantly so did increased reaction time. Further, a positively correlated cross-term between the reaction time and precursor equivalence indicates that an increased reaction time can compensate for lower acyl ketene precursor equivalence. This was unexpected, as residual precursor is not observed even under relatively mild conditions. While no explicit investigation was attempted with regard to the lifetime of the acyl ketene species, the combination of this time dependence and the rapid consumption of precursor, taken with previous observations on the lifetime of $\alpha$-oxoketene species ${ }^{38}$ such as $\mathbf{3}$ raises the possibility that a precursor species such as 4 persists in the reaction mixture for some time. 

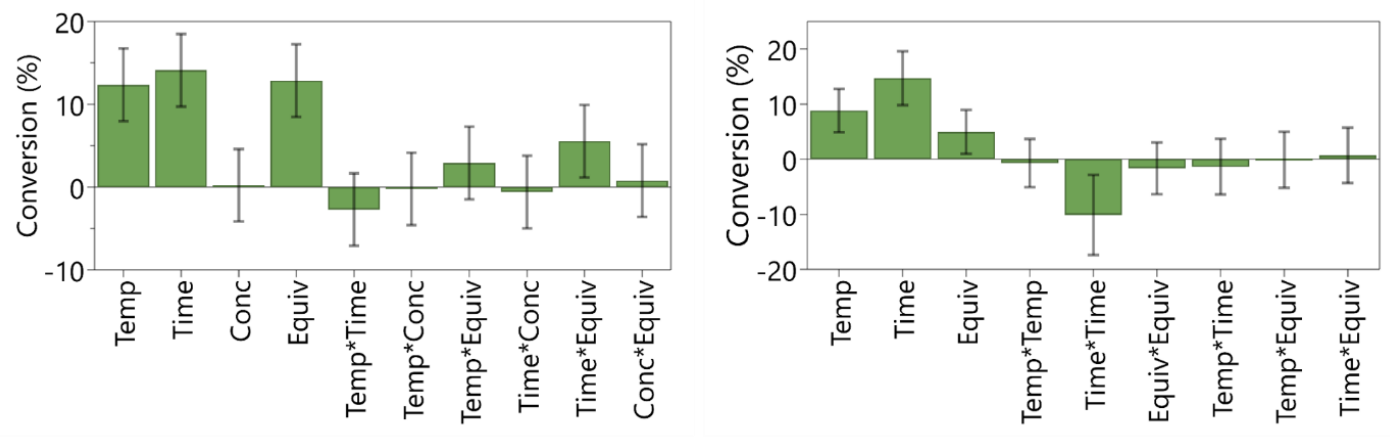

a

b

Figure 5. Multiple linear regression (MLR) models of the flow conditions used for synthesis of 2-pyridone $\mathbf{1 1}$ (a) Regression coefficients of the model from the screening design ( $R 2=0.95, Q 2=0.87$ ) showing the investigated variables and their correlation to the conversion of thiazoline to 2-pyridone. (b) Regression coefficients of the model from the optimization design $(\mathrm{R} 2=0.96, \mathrm{Q} 2=0.64)$.

Table 1. Screening and optimisation designs

\begin{tabular}{|c|c|c|c|c|c|c|c|c|c|c|c|c|c|}
\hline & Entry & $\begin{array}{c}\text { Temp } \\
\left({ }^{\circ} \mathrm{C}\right)\end{array}$ & $\begin{array}{c}\text { Time } \\
\text { (s) }\end{array}$ & $\begin{array}{c}\text { Thiaz- } \\
\text { oline } \\
\text { conc } \\
\text { (M) }\end{array}$ & $\begin{array}{l}\text { Meld- } \\
\text { rums } \\
\text { acid } \\
\text { Equiv }\end{array}$ & $\begin{array}{c}\text { Conv } \\
(\%)\end{array}$ & & Entry & $\begin{array}{c}\text { Temp } \\
\left({ }^{\circ} \mathrm{C}\right)\end{array}$ & $\begin{array}{c}\text { Time } \\
\text { (s) }\end{array}$ & $\begin{array}{c}\text { Thiaz- } \\
\text { oline } \\
\text { conc } \\
\text { (M) }\end{array}$ & $\begin{array}{l}\text { Meld- } \\
\text { rums } \\
\text { acid } \\
\text { Equiv }\end{array}$ & $\begin{array}{c}\text { Conv } \\
(\%)\end{array}$ \\
\hline \multirow{19}{*}{ 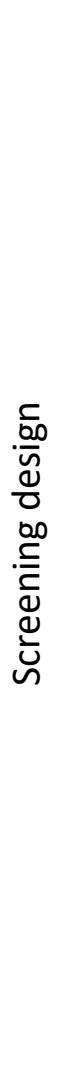 } & 1 & 100 & 60 & 0.2 & 1 & 0.5 & \multirow{19}{*}{ 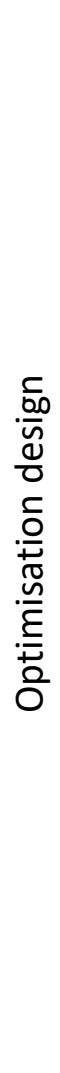 } & 20 & 130 & 114 & 0.18 & 1.5 & 40 \\
\hline & 2 & 140 & 60 & 0.2 & 1 & 28 & & 21 & 130 & 742 & 0.18 & 1.5 & 65 \\
\hline & 3 & 100 & 300 & 0.2 & 1 & 26 & & 22 & 100 & 114 & 0.18 & 1.5 & 23 \\
\hline & 4 & 140 & 300 & 0.2 & 1 & 39 & & 23 & 100 & 742 & 0.18 & 1.5 & 51 \\
\hline & 5 & 100 & 60 & 0.38 & 1 & 3 & & 24 & 130 & 114 & 0.18 & 2.5 & 48 \\
\hline & 6 & 140 & 60 & 0.38 & 1 & 26 & & 25 & 130 & 742 & 0.18 & 2.5 & 71 \\
\hline & 7 & 100 & 300 & 0.38 & 1 & 24 & & 26 & 100 & 114 & 0.18 & 2.5 & 28 \\
\hline & 8 & 140 & 300 & 0.38 & 1 & 36 & & 27 & 100 & 742 & 0.18 & 2.5 & 61 \\
\hline & 9 & 100 & 60 & 0.2 & 3 & 11 & & 28 & 140 & 500 & 0.18 & 2 & 75 \\
\hline & 10 & 140 & 60 & 0.2 & 3 & 44 & & 29 & 115 & 30 & 0.18 & 2 & 17 \\
\hline & 11 & 100 & 300 & 0.2 & 3 & 54 & & $30^{1}$ & 115 & 1486 & 0.18 & 2 & 74 \\
\hline & 12 & 140 & 300 & 0.2 & 3 & 81 & & 31 & 90 & 500 & 0.18 & 2 & 41 \\
\hline & 13 & 100 & 60 & 0.38 & 3 & 12 & & 32 & 115 & 500 & 0.18 & 1.2 & 44 \\
\hline & 14 & 140 & 60 & 0.38 & 3 & 49 & & 33 & 115 & 500 & 0.18 & 2.8 & 67 \\
\hline & 15 & 100 & 300 & 0.38 & 3 & 56 & & 34 & 115 & 500 & 0.18 & 2 & 67 \\
\hline & 16 & 140 & 300 & 0.38 & 3 & 81 & & 35 & 115 & 500 & 0.18 & 2 & 60 \\
\hline & 17 & 120 & 187.5 & 0.29 & 2 & 52 & & 36 & 115 & 500 & 0.18 & 2 & 64 \\
\hline & 18 & 120 & 187.5 & 0.29 & 2 & 47 & & & & & & & \\
\hline & 19 & 120 & 187.5 & 0.29 & 2 & 50 & & & & & & & \\
\hline
\end{tabular}

${ }^{1}$ outlier, removed from the model 


\section{Optimisation screen}

In light of the results from the initial screen, we chose to further interrogate the relationship between time, temperature and acyl ketene precursor equivalence to hone our preferred conditions, this time investigating some intermediate temperatures, times and equivalents in an attempt to identify any deviations from linear dependency. Thus, we set-up a central composite design with the three variables in five different levels (See Figure 4b and Table 1, Row 20-36) for a total of 17 experiments. MLR of the different variables correlated with the calculated conversions gave a model with nine coefficients having a R2Y of 0.95 and Q2 of 0.64 (Figure 5b) after removing one outlier (Entry 30, in Table 1). Also here we could obviously see the same positive correlation of time, temperature, and equivalents of Meldrum's acid derivative with the conversion. Interestingly, a negatively correlated square term of the time indicates that the optimal reaction time actually is within the investigated interval when the experiment with the longest reaction time was removed as an outlier.

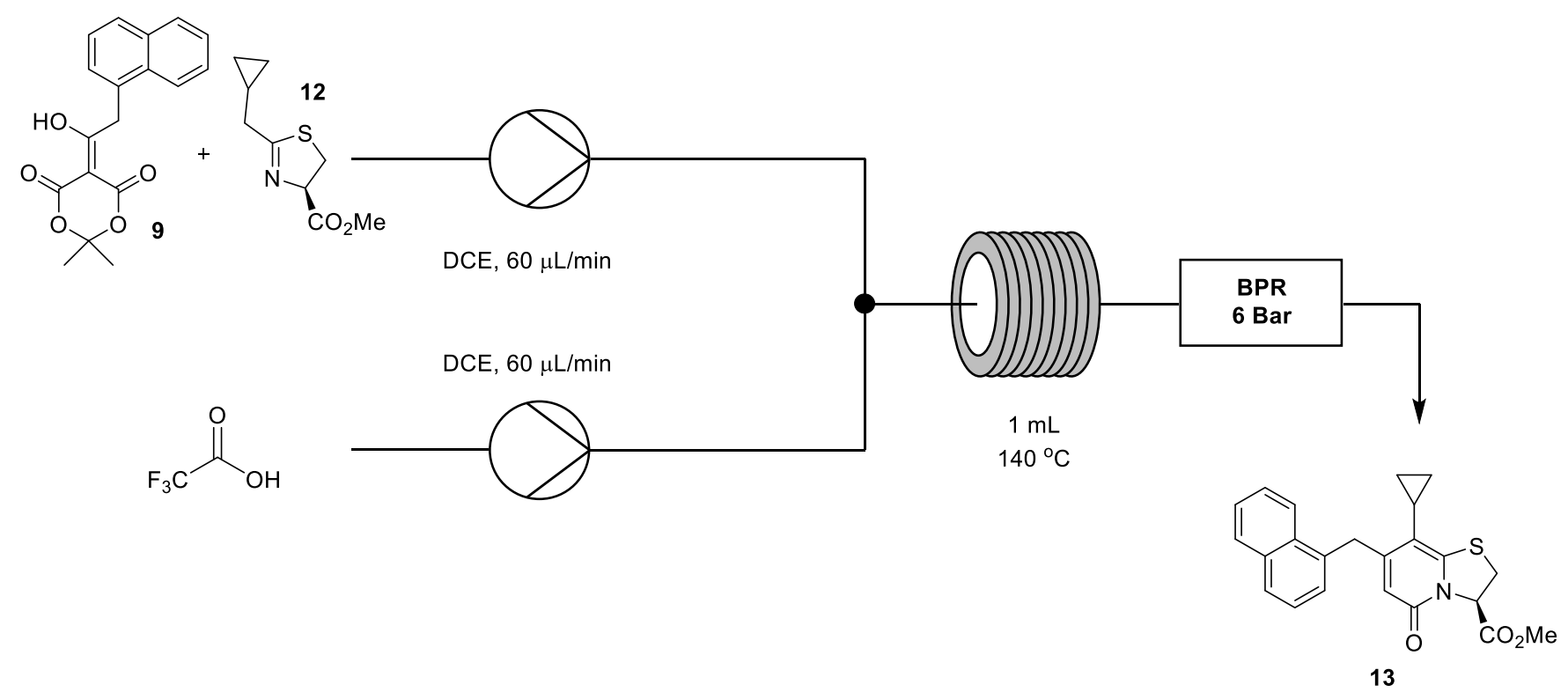

Scheme 2. The set-up for the flow system during continous flow.

The results from both the designs lead us to use the higher temperature tested $\left(140{ }^{\circ} \mathrm{C}\right)$ and a longer reaction time $(500 \mathrm{~s})$. This allowed us to reduce equivalence to 2 without loss of conversion relative to batch MWI experiments.

Table 2. Flow vs batch (microwave) synthesis of C10 methyl ester

\begin{tabular}{ccccccc}
\hline Material & TFA eqv. & MA eqv. & T $\left({ }^{\circ} \mathrm{C}\right)$ & $\mathrm{t}(\mathrm{s})$ & ee $(\%)$ & Yield \\
\hline MWI & $1^{\mathrm{b}}$ & 2 & 120 & 180 & 83 & $59 \%$ \\
Flow & 3 & 2 & 140 & 500 & 73 & $93 \%$ \\
\hline
\end{tabular}

${ }^{a}$ Based on chiral HPLC measurements. ${ }^{b}$ Normal lab conditions; running with 3 eqv. TFA does not change the observed yield under these conditions.

Although the napthyl pyridone is useful, ${ }^{47}$ we decided for purposes of scale up to directly synthesize C10 methyl ester 13 (Scheme 2), a molecule with very interesting anti-mycobacterial activity and frequently 
elaborated upon for synthesis of new analogues. This synthesis is generally somewhat higher yielding, and we carried out small scale trials which confirmed good conversion with 2 eqv. We carried out this synthesis on gram scale and then in batch microwave conditions with our prior procedure (Table 2). One important feature of this 2-pyridone synthesis is retention of stereochemistry from the thiazoline unit. ${ }^{15}$ In practice, in more recent procedures this retention is not absolute, but a reasonable enantiomer excess is retained, and we also used chiral HPLC to check the enantiopurity of the resulting material. When using the same lower acyl-ketene precursor equivalents in all experiments, we were able to observe a $30 \%+$ improvement in yield, which frankly exceeded our initial expectations. Unfortunately, some trade off in enantiopurity was observed, with more epimerization in the flow material. However, definite advantages are possible in scaling: simply by switching from a $1 \mathrm{~mL}$ reaction chamber to a larger, off-the-shelf $(16 \mathrm{~mL}$ ) loop our results suggest up to 192 grams of material could be produced in a 24 hour period. The previous microwave approach would require 320 separate batch reactions to achieve similar quantities, and would require more starting material, be more time consuming and imply more safety issues. Scaling instead in larger, thermal batch reactions would exacerbate the issues with pressure, and be far less predictable and less efficient in scaling.

\section{Conclusions}

Application of continuous flow technology and a Design of Experiment approach to optimisation has allowed us to develop an efficient procedure for the acyl ketene-imine cycloaddition based synthesis of the thiazolo fused 2-pyridone scaffold. Accessing quantities of these materials can be challenging and we anticipate this approach could be a valuable development in our exploration of the potential applications of this scaffold. Further, the difference in yield and enantiopurity $v s$ batch procedures raises questions about how these changes occur, which will be a focus of future investigation, particularly with regard to separating these properties, retaining efficient conversion while retaining higher ee. Our model suggests high yields might also be possible at lower reaction temperatures, given a longer reaction time, and this is a promising starting point for further investigation. Other future developments will likely include application to scaffold variants generated under other synthetic conditions, ${ }^{4,48}$ and addition of in-flow work-up procedures followed by further synthetic steps, such as ester hydrolysis to the procedure.

\section{Experimental Section}

General. All flow reactions were performed using a Syrris Asia flow system ${ }^{49}$ under an inert atmosphere with dry solvents. Unless otherwise stated, purchased reactants and reagents were used as received from commercial suppliers. Microwave reactions were performed in sealed vessels using a Biotage ${ }^{\circledR}$ Initiator microwave synthesizer, temperatures were monitored by an internal IR probe, stirring was mediated magnetically. TLC was performed on purchased aluminum backed silica gel plates (median pore size $60 \AA$, fluorescent indicator $254 \mathrm{~nm}$ ) and detected with UV light at 254 and $366 \mathrm{~nm}$. Flash column chromatography (eluents given in brackets) employed normal phase silica gel (40-63 $\mu \mathrm{m}$, VWR Chemicals). Automated flash column chromatography was performed using a Biotage ${ }^{\circledR}$ Isolera One system and purchased pre-packed silica gel cartridges (Biotage ${ }^{\circledR}$ SNAP Cartridge, KP-Sil). Optical rotation was measured with a Rudolph Autopol IV polarimeter 343 at $22^{\circ} \mathrm{C}$ and $589 \mathrm{~nm}$. [ $\alpha$ ] is reported in deg. $\mathrm{mL} \cdot \mathrm{g}^{-1} \cdot \mathrm{dm}^{-1}$, concentrations $(c)$ are given in $\mathrm{g} / 100 \mathrm{~mL}$. ${ }^{1} \mathrm{H}$ and ${ }^{13} \mathrm{C}$ NMR spectra were recorded on a Bruker Avance III Ultrashield $500 \mathrm{MHz}$ or a Bruker Avance III 400 
$\mathrm{MHz}$ spectrometer with a BBO-F/H Smartprobe ${ }^{\mathrm{TM}}$ or a Bruker Avance III HD $600 \mathrm{MHz}$ spectrometer with a CP $\mathrm{BBO}-\mathrm{H} / \mathrm{F}, 5 \mathrm{~mm}$ cryoprobe, at $298 \mathrm{~K}$, unless other temperature is given. All spectrometers were operated by Topspin 3.5. Resonances are given in ppm relative to TMS, and calibrated to solvent residual signals $\left[\mathrm{CDCl}_{3}: \delta_{\mathrm{H}}\right.$ $\left.=7.26 \mathrm{ppm} ; \delta_{\mathrm{C}}=77.16 \mathrm{ppm} .\left(\mathrm{CD}_{3}\right)_{2} \mathrm{SO}: \delta_{\mathrm{H}}=2.50 \mathrm{ppm} ; \delta_{\mathrm{C}}=39.51 \mathrm{ppm} .\left(\mathrm{CD}_{3}\right) \mathrm{CO} \delta_{\mathrm{H}}=2.05 \mathrm{ppm} ; \delta_{\mathrm{C}}=29.84 \mathrm{ppm}\right]$. The following abbreviations are used to indicate splitting patterns: $s=$ singlet; $d=$ doublet; $d d=$ double doublet; $\mathrm{t}=$ triplet; $\mathrm{m}=$ multiplet; $\mathrm{bs}=$ broad singlet. Chiral HPLC of cyclopropyl thiazoline 11 was carried out using a Diacel Chiracel OD-H $(250 \times 4.6 \mathrm{~mm})$ column and eluting isocratically (Hexane:PrOH 90:10) at ambient temperature, then detected by UV at $254 \mathrm{~nm}$. Injection was $10 \mu \mathrm{L}$ at $1 \mathrm{mg} / \mathrm{mL}$ in $\mathrm{CHCl}_{3}$. Chiral HPLC of pyridone 13 was carried out using a Lux $5 \mu \mathrm{m}$ i-amylose-1 $(250 \times 4.6 \mathrm{~mm})$ column and eluting with a gradient ('PrOH 30:70 to $100 \%$ hexane) at ambient temperature, then detected by UV at $254 \mathrm{~nm}$. Injection was $10 \mu \mathrm{L}$ at $1 \mathrm{mg} / \mathrm{mL}$ in $\mathrm{MeOH}$.

Optimisation of flow conditions for the synthesis of 2-pyridone (11). The flow equipment was set up according to Scheme 1. Naphthyl Meldrum's acid derivative $\mathbf{9}$ and methyl thiazoline $\mathbf{1 0}$ were taken up in DCE (1 mL) at various concentrations (see Table 1) and filled into loop 1. Acid (see Table 1) was taken up in DCE (1 mL) at various concentrations and filled into loop 2. The two loops were simultaneously injected to pass through a 1 $\mathrm{mL}$ chip reactor at different flow rates, pressurised by a 6 bar back pressure regulator and the outflow at a steady reaction state was collected. $50 \mu$ of the reaction mixture was diluted with $450 \mu \mathrm{CDCl}_{3}$ and analyzed with ${ }^{1} \mathrm{H}-\mathrm{NMR}$, comparing the $\alpha$ proton of the thiazoline to the $\mathrm{C} 6$ hydrogen in the pyridone in order to calculate the conversion rate of thiazoline $\mathbf{1 0}$ to 2-pyridone 11.

Scale-up procedure for the continuous flow synthesis of 2-pyridone (13). The flow equipment was set up according to Scheme 2. Naphtyl Meldrum's acid derivative $9(0.72 \mathrm{M})$ and cyclopropyl thiazoline 12 (0.36 M) were dissolved in DCE $(15 \mathrm{~mL})$. TFA $(1.08 \mathrm{M})$ was dissolved in DCE $(15 \mathrm{~mL})$. The two solutions were simultaneously pumped (flow rate $60 \mu \mathrm{L}$ to achieve a residence time of $500 \mathrm{~s}$ in the reactor) through a $1 \mathrm{~mL}$ chip reactor, pressurised by a 6 bar back pressure regulator, and $27.5 \mathrm{~mL}$ of the outflow at a steady reaction state was collected. The reaction solution was quenched with aqueous $\mathrm{NaHCO}_{3}$ (sat., $30 \mathrm{~mL}$ ) and the organic phase was collected and the aqueous phase re-extracted with $\mathrm{CH}_{2} \mathrm{Cl}_{2}(2 \times 30 \mathrm{~mL})$. The combined organic phases was washed with brine $(30 \mathrm{~mL})$ and dried over $\mathrm{Na}_{2} \mathrm{SO}_{4}$ before concentration then, purified by column chromatography (heptane:EtOAc, $1: 2$ to $1: 4$ ) to give 13 (1.8 g, $4.60 \mathrm{mmol}, 93 \%$ yield) as a white solid. ${ }^{1} \mathrm{H}$ and ${ }^{13} \mathrm{C}$ NMR were in accordance with data previously published. ${ }^{47}$

MWI synthesis of 2-pyridone (13). In a microwave reaction tube equipped with a magnetic stirrer, thiazoline 12 (1.5 mmol, 1.0 equiv.) and Meldrum's acid derivative 9 (0.94 g, 3.0 mmol, 2.0 equiv.) were dissolved in DCE $(6 \mathrm{ml})$. TFA ( $115 \mu \mathrm{l}, 1.5 \mathrm{mmol}, 1.0$ eq.) was added, the tube was sealed and heated to $120{ }^{\circ} \mathrm{C}$ under microwave irradiation for $3 \mathrm{~min}$. The reaction mixture was cooled to room temperature, diluted with DCM and washed with aqueous $\mathrm{NaHCO}_{3(\mathrm{aq})}$ (sat.), followed by brine. The aqueous phases were re-extracted with DCM. The organic phases were combined, dried, filtered and evaporated and purified by column chromatography as in the above procedure.

Epimerization of thiazoline (12). In a round bottom flask equipped with magnetic stirrer, thiazoline $(2.0 \mathrm{mmol}$, 1.0 equiv.) was dissolved in $\mathrm{DCM}(2 \mathrm{ml})$. To this, $\mathrm{K}_{2} \mathrm{CO}_{3}(8.0 \mathrm{mmol}, 4.0$ equiv.) was added and the mixture stirred at $r$ for 4 days. The reaction mixture was diluted with DCM and washed with brine twice. The organic phase was dried over $\mathrm{Na}_{2} \mathrm{SO}_{4}$, filtered and evaporated, then purified by column chromatography (heptane to EtOAc). Naphthyl Meldrum's acid derivative (9). Meldrum's acid analogue 9 was prepared according to the earlier reported procedures. ${ }^{13}$ Crude product was recrystallized from a DCM:heptane (1:4) mixture. 
Thiazolines 10 and 12 were synthesized according to literature procedures ${ }^{4}$ and match previously published data. 50

\section{Acknowledgements}

This project has been supported under the framework of the JPIAMR - Joint Programming Initiative on Antimicrobial Resistance. In addition, FA is grateful to the Swedish Research Council (2017-02339; 2017-00695 and 2018-04589), the Knut and Alice Wallenberg foundation (KAW 2013.0031), the Göran Gustafsson foundation, the Kempe Foundation (SMK-1755), the Swedish Foundation for Strategic Research (SB12-0070), the National Institutes of Health (R01Al134847-01A1), the Erling Perssons Stiftelse (P20-00473). and the Michael J Fox foundation for financial support. AL gratefully acknowledges the Swedish ministry of defence for financial support.

\section{Supplementary Material}

${ }^{1} \mathrm{H}$ and ${ }^{13} \mathrm{C}$ NMR spectra of the material synthesis in flow and the chiral HPLC traces used for ee determination can be found in the supplementary material.

\section{References}

1. Chorell, E.; Pinkner, J. S.; Phan, G.; Edvinsson, S.; Buelens, F.; Remaut, H.; Waksman, G.; Hultgren, S. J.; Almqvist, F., J Med Chem 2010, 53 (15), 5690-5.

https://doi.org/10.1021/jm100470t

2. Pinkner, J. S.; Remaut, H.; Buelens, F.; Miller, E.; Aberg, V.; Pemberton, N.; Hedenstrom, M.; Larsson, A.; Seed, P.; Waksman, G.; Hultgren, S. J.; Almqvist, F., Proceedings of the National Academy of Sciences 2006, 103 (47), 17897-17902.

https://doi.org/10.1073/pnas.0606795103

3. Good, J. A. D.; Kulen, M.; Silver, J.; Krishnan, K. S.; Bahnan, W.; Nunez-Otero, C.; Nilsson, I.; Wede, E.; de Groot, E.; Gylfe, A.; Bergstrom, S.; Almqvist, F., J Med Chem 2017, 60 (22), 9393-9399. https://doi.org/10.1021/acs.jmedchem.7b00716

4. Kulen, M.; Lindgren, M.; Hansen, S.; Cairns, A. G.; Grundstrom, C.; Begum, A.; van der Lingen, I.; Brannstrom, K.; Hall, M.; Sauer, U. H.; Johansson, J.; Sauer-Eriksson, A. E.; Almqvist, F., J Med Chem 2018, 61 (9), 4165-4175.

https://doi.org/10.1021/acs.jmedchem.8b00289

5. Good, J. A.; Andersson, C.; Hansen, S.; Wall, J.; Krishnan, K. S.; Begum, A.; Grundstrom, C.; Niemiec, M. S.; Vaitkevicius, K.; Chorell, E.; Wittung-Stafshede, P.; Sauer, U. H.; Sauer-Eriksson, A. E.; Almqvist, F.; Johansson, J., Cell Chem Biol 2016, 23 (3), 404-14.

https://doi.org/10.1016/i.chembiol.2016.02.013

6. Andersson, E. K.; Bengtsson, C.; Evans, M. L.; Chorell, E.; Sellstedt, M.; Lindgren, A. E.; Hufnagel, D. A.; Bhattacharya, M.; Tessier, P. M.; Wittung-Stafshede, P.; Almqvist, F.; Chapman, M. R., Chem Biol 2013, 20 (10), 1245-54. 
https://doi.org/10.1016/j.chembiol.2013.07.017

7. Horvath, I.; Sellstedt, M.; Weise, C.; Nordvall, L. M.; Krishna Prasad, G.; Olofsson, A.; Larsson, G.; Almqvist, F.; Wittung-Stafshede, P., Arch Biochem Biophys 2013, 532 (2), 84-90.

https://doi.org/10.1016/i.abb.2013.01.012

8. Horvath, I.; Weise, C. F.; Andersson, E. K.; Chorell, E.; Sellstedt, M.; Bengtsson, C.; Olofsson, A.; Hultgren, S. J.; Chapman, M.; Wolf-Watz, M.; Almqvist, F.; Wittung-Stafshede, P., J Am Chem Soc 2012, 134 (7), 343944.

https://doi.org/10.1021/ja209829m

9. Singh, P.; Chorell, E.; Krishnan, K. S.; Kindahl, T.; Aden, J.; Wittung-Stafshede, P.; Almqvist, F., Org Lett 2015, 17 (24), 6194-7. https://doi.org/10.1021/acs.orglett.5b03190

10. Olsen, L. K.; Cairns, A. G.; Aden, J.; Moriarty, N.; Cabre, S.; Alamilla, V. R.; Almqvist, F.; Dowd, E.; McKernan, D. P., Brain Behav Immun 2019, 80, 525-535. https://doi.org/10.1016/i.bbi.2019.04.036

11. Cairns, A. G.; Vazquez-Romero, A.; Mahdi Moein, M.; Aden, J.; Elmore, C. S.; Takano, A.; Arakawa, R.; Varrone, A.; Almqvist, F.; Schou, M., ACS Chem Neurosci 2018, 9 (11), 2542-2547. https://doi.org/10.1021/acschemneuro.8b00236

12. Sellstedt, M.; Almqvist, F., Org Lett 2008, 10 (18), 4005-7.

https://doi.org/10.1021/ol801506y

13. Singh, P.; Adolfsson, D. E.; Aden, J.; Cairns, A. G.; Bartens, C.; Brannstrom, K.; Olofsson, A.; Almqvist, F., J Org Chem 2019, 84 (7), 3887-3903.

https://doi.org/10.1021/acs.joc.8b03015

14. Flentie, K.; Harrison, G. A.; Tukenmez, H.; Livny, J.; Good, J. A. D.; Sarkar, S.; Zhu, D. X.; Kinsella, R. L.; Weiss, L. A.; Solomon, S. D.; Schene, M. E.; Hansen, M. R.; Cairns, A. G.; Kulen, M.; Wixe, T.; Lindgren, A. E. G.; Chorell, E.; Bengtsson, C.; Krishnan, K. S.; Hultgren, S. J.; Larsson, C.; Almqvist, F.; Stallings, C. L., Proc Natl Acad Sci U S A 2019, 116 (21), 10510-10517. https://doi.org/10.1073/pnas.1818009116

15. Emtenas, H.; Alderin, L.; Almqvist, F., J Org Chem 2001, 66 (20), 6756-61.

https://doi.org/10.1021/jo015794u

16. Singh, P.; Cairns, A. G.; Adolfsson, D. E.; Aden, J.; Sauer, U. H.; Almqvist, F., Org Lett 2019, 21 (17), 69466950.

https://doi.org/10.1021/acs.orglett.9b02549

17. Sellstedt, M.; Almqvist, F., Organic Letters 2009, 11 (23), 5470-5472. https://doi.org/10.1021/ol9023024

18. In press, J Org Chem, https://doi.org/10.1021/acs.joc.0c01699

19. Emtenas, H.; Taflin, C.; Almqvist, F., Mol Divers 2003, 7 (2-4), 165-9.

https://doi.org/10.1023/B:MODI.0000006800.46154.99

20. Glasnov, T. N.; Kappe, C. O., Chemistry 2011, 17 (43), 11956-68.

https://doi.org/10.1002/chem.201102065

21. Movsisyan, M.; Delbeke, E. I.; Berton, J. K.; Battilocchio, C.; Ley, S. V.; Stevens, C. V., Chem Soc Rev 2016, 45 (18), 4892-928. https://doi.org/10.1039/C5CS00902B

22. Plutschack, M. B.; Pieber, B.; Gilmore, K.; Seeberger, P. H., Chem Rev 2017, 117 (18), 11796-11893. 
https://doi.org/10.1021/acs.chemrev.7b00183

23. Trojanowicz, M., Molecules 2020, 25 (6).

https://doi.org/10.3390/molecules25061434

24. Akwi, F. M.; Watts, P., Chem Commun (Camb) 2018, 54 (99), 13894-13928. https://doi.org/10.1039/C8CC07427E

25. Noël, T.; Su, Y.; Hessel, V., Beyond Organometallic Flow Chemistry: The Principles Behind the Use of Continuous-Flow Reactors for Synthesis. In Organometallic Flow Chemistry, Noël, T., Ed. Springer International Publishing: Cham, 2016; pp 1-41. https://doi.org/10.1007/978-3-319-33243-7

26. Hartman, R. L.; McMullen, J. P.; Jensen, K. F., Angew Chem Int Ed Engl 2011, 50 (33), 7502-19. https://doi.org/10.1002/anie.201004637

27. Brandão, P.; Pineiro, M.; Pinho e Melo, T. M. V. D., European Journal of Organic Chemistry 2019, 2019 (43), 7188-7217.

https://doi.org/10.1002/ejoc.201901335

28. Lehmann, J.; Alzieu, T.; Martin, R. E.; Britton, R., Org Lett 2013, 15 (14), 3550-3. https://doi.org/10.1021/ol4013525

29. Garcia-Lacuna, J.; Dominguez, G.; Perez-Castells, J., ChemSusChem 2020.

30. Galaverna, R.; Fernandes, L. P.; Browne, D. L.; Pastre, J. C., Reaction Chemistry \& Engineering 2019, 4 (2), 362-367. https://doi.org/10.1039/C8RE00237A

31. Galaverna, R.; McBride, T.; Pastre, J. C.; Browne, D. L., Reaction Chemistry \& Engineering 2019, 4 (9), 15591564.

https://doi.org/10.1039/C9RE00072K

32. Lai, X.; Shi, Z.; Pu, Z.; Zhang, P.; Zhang, X.; Yu, H.; Li, D., Microsystems \& Nanoengineering 2020, 6 (1). https://doi.org/10.1038/s41378-020-0136-4

33. Adamo, A.; Beingessner, R. L.; Behnam, M.; Chen, J.; Jamison, T. F.; Jensen, K. F.; Monbaliu, J. C.; Myerson, A. S.; Revalor, E. M.; Snead, D. R.; Stelzer, T.; Weeranoppanant, N.; Wong, S. Y.; Zhang, P., Science 2016, 352 (6281), 61-7.

https://doi.org/10.1126/science.aaf1337

34. Wiles, C.; Watts, P., Green Chem. 2012, 14 (1), 38-54. https://doi.org/10.1039/C1GC16022B

35. Yoshida, J.; Takahashi, Y.; Nagaki, A., Chem Commun (Camb) 2013, 49 (85), 9896-904. https://doi.org/10.1039/C3CC44709J

36. Baumann, M.; Moody, T. S.; Smyth, M.; Wharry, S., Organic Process Research \& Development 2020, 24 (10), 1802-1813. https://doi.org/10.1021/acs.oprd.9b00524

37. Gutmann, B.; Cantillo, D.; Kappe, C. O., Angew Chem Int Ed Engl 2015, 54 (23), 6688-728. https://doi.org/10.1002/anie.201409318

38. Xu, F.; Armstrong, J. D., 3rd; Zhou, G. X.; Simmons, B.; Hughes, D.; Ge, Z.; Grabowski, E. J., J Am Chem Soc 2004, 126 (40), 13002-9.

https://doi.org/10.1021/ja046488b

39. Pemberton, N.; Jakobsson, L.; Almqvist, F., Org Lett 2006, 8 (5), 935-8. https://doi.org/10.1021/ol052998e

40. Hyatt, J. A.; Feldman, P. L.; Clemens, R. J., The Journal of Organic Chemistry 1984, 49 (26), 5105-5108. 
https://doi.org/10.1021/jo00200a018

41. Reber, K. P.; Tilley, S. D.; Sorensen, E. J., Chem Soc Rev 2009, 38 (11), 3022-34.

https://doi.org/10.1039/b912599j

42. Schwolow, S.; Hollmann, J.; Schenkel, B.; Röder, T., Organic Process Research \& Development 2012, 16 (9), 1513-1522.

https://doi.org/10.1021/op300107z

43. Lamberto, D. J.; Alvarez, M. M.; Muzzio, F. J., Chemical Engineering Science 1999, 54 (7), 919-942. https://doi.org/10.1016/S0009-2509(98)00275-9

44. Epps, R. W.; Volk, A. A.; Abdel-Latif, K.; Abolhasani, M., Reaction Chemistry \& Engineering 2020, 5 (7), 1212-1217. https://doi.org/10.1039/DORE00129E

45. Hone, C. A.; Boyd, A.; O'Kearney-McMullan, A.; Bourne, R. A.; Muller, F. L., Reaction Chemistry \& Engineering 2019, 4 (9), 1565-1570.

https://doi.org/10.1039/C9RE00180H

46. Chorell, E.; Edvinsson, S.; Almqvist, F., Tetrahedron Letters 2010, 51 (18), 2461-2463. https://doi.org/10.1016/i.tetlet.2010.02.162

47. Bengtsson, C.; Almqvist, F., J Org Chem 2010, 75 (3), 972-5. https://doi.org/10.1021/jo902458g

48. Pemberton, N.; Pinkner, J. S.; Edvinsson, S.; Hultgren, S. J.; Almqvist, F., Tetrahedron 2008, 64 (40), $9368-$ 9376.

https://doi.org/10.1016/i.tet.2008.07.015

49. Syrris webpage: http://syrris.com/flow-products/asia-flow-chemistry (accessed Oct 20).

50. Emtenas, H.; Ahlin, K.; Pinkner, J. S.; Hultgren, S. J.; Almqvist, F., J Comb Chem 2002, 4 (6), 630-9. https://doi.org/10.1021/cc020032d 